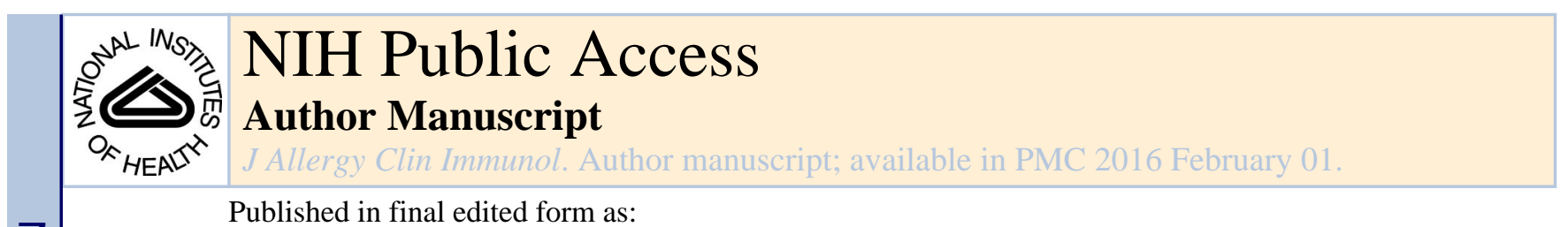

Published in final edited form as:

J Allergy Clin Immunol. 2015 February ; 135(2): 379-385. doi:10.1016/j.jaci.2014.07.039.

\title{
Interleukin-1 receptor antagonist reduces endotoxin-induced airway inflammation in healthy volunteers
}

\author{
Michelle L. Hernandez, MD ${ }^{\mathrm{a}}$, Katherine Mills, BA ${ }^{\mathrm{a}}$, Martha Almond, RRT ${ }^{\mathrm{a}}$, Krista Todoric, \\ MD $^{a}$, Maria M. Aleman, PhD ${ }^{a}$, Hongtao Zhang, BS $^{b}$, Haibo Zhou, PhD $^{b}$, and David B. Peden, \\ MD, MS \\ ${ }^{a}$ Center for Environmental Medicine, Asthma, \& Lung Biology, The University of North Carolina at \\ Chapel Hill, Chapel Hill, NC \\ ${ }^{b}$ Department of Biostatistics, Gillings School of Global Public Health, The University of North \\ Carolina at Chapel Hill, Chapel Hill, NC
}

\begin{abstract}
Background-Asthma with neutrophil predominance is challenging to treat with corticosteroids. Novel treatment options for asthma include those that target innate immune activity. Recent literature has indicated a significant role for IL-1 $\beta$ in both acute and chronic neutrophilic asthma.

Objective-This study used inhaled endotoxin (LPS) challenge as a model of innate immune activation to a) assess the safety of the interleukin-1 receptor antagonist, anakinra, in conjunction with inhaled LPS and b) to test the hypothesis that IL-1 blockade will suppress acute neutrophil response to challenge with inhaled LPS.
\end{abstract}

Methods-In a phase I clinical study, 17 healthy volunteers completed a double-blinded, placebo controlled crossover study where they received 2 daily subcutaneous doses of $1 \mathrm{mg} / \mathrm{kg}$ anakinra (maximum dose of $100 \mathrm{mg}$ ) or saline (placebo). One hour after the second treatment dose, subjects underwent an inhaled LPS challenge. Induced sputum was assessed for neutrophils 4 hours after inhaled LPS. The effect of anakinra compared to placebo on airway neutrophils and airway proinflammatory cytokines after LPS challenge was compared using a linear mixed model approach.

Results-Anakinra pretreatment significantly diminished airway neutrophilia compared to placebo. LPS-induced IL-1 $\beta$, IL-6, and IL-8 were significantly reduced during the anakinra treatment period compared to placebo. Subjects tolerated the anakinra treatment well, without increased frequency of infections that were attributable to anakinra treatment.

(C) 2014 American Academy of Allergy, Asthma and Immunology. Published by Mosby, Inc. All rights reserved.

Corresponding Author: Michelle Hernandez, MD, 104 Mason Farm Road, CB \#7310, Chapel Hill, NC 27599-7310, 919-843-5383, 919-966-9863 (fax), michelle_hernandez@med.unc.edu.

Disclosures: Dr. Peden has received funding from the National Institutes of Health, the Environmental Protection Agency, and honoraria from the American Academy of Allergy, Asthma and Immunology.

The rest of the authors have declared that they have no conflicts of interest.

Publisher's Disclaimer: This is a PDF file of an unedited manuscript that has been accepted for publication. As a service to our customers we are providing this early version of the manuscript. The manuscript will undergo copyediting, typesetting, and review of the resulting proof before it is published in its final citable form. Please note that during the production process errors may be discovered which could affect the content, and all legal disclaimers that apply to the journal pertain. 
Conclusions-Anakinra effectively reduced airway neutrophilic inflammation and resulted in no serious adverse events in a model of inhaled LPS challenge. Anakinra is a potential therapeutic candidate for treatment of asthma with neutrophil predominance in diseased populations.

\section{Keywords}

Endotoxin; Neutrophil; Asthma; Induced Sputum; LPS; IL-1 $\beta$; IL-1 receptor antagonist; anakinra; innate immunity

\section{Introduction}

Asthma is the leading cause of hospitalization in children and is a significant cause for morbidity in adults, accounting for 5,000 deaths per year in the U.S. The majority of asthma exacerbations are triggered by viral infections, pollutants which can injure or activate airway epithelial cells, or bioaerosols which likely activate airway monocytes and macrophages (1, 2). Among environmental causes of asthma exacerbation, endotoxin (lipopolysaccharide, LPS) present in airborne particles in both urban and agricultural settings is one of the most significant causes of acute disease in persons with established asthma (3).

LPS is a pathogen-associated molecular pattern moiety which activates airway monocytes and macrophages through interaction with cell surface receptors CD14 and toll-like receptor (TLR)-4. Inhalation challenge studies of human volunteers demonstrate that LPS induces increased airway neutrophils, increased pro-inflammatory cytokine levels (tumor necrosis factor (TNF)- $\alpha$, interleukin (IL)-6, IL-1 $\beta$ ), increased expression of monocyte or macrophage CD14 and TLR-4, and increased oxidative stress, thus serving as a model of a neutrophilic asthma exacerbation (4-7). Inhaled LPS challenge provides a mechanism to study neutrophil-predominant airways inflammation in early phase clinical studies prior to enrolling diseased populations.

Innate immune activation has become increasingly recognized as a pathogenic factor in both viral-induced asthma exacerbation (8) and asthma with neutrophil predominance (9). Gene expression profiling of induced sputum has demonstrated an association between airway neutrophilic inflammation and upregulation of IL-1 and TNF-a pathways (9). Therapies targeting refractory asthma have included TNF-a blockade. However, anti-TNF-a treatment in severe asthma patients treated with high doses of corticosteroids showed poor efficacy (10) and an unfavorable risk-benefit profile due to immune suppression and malignancy (10).

IL-1 blockade represents a novel target for asthma therapy. IL-1 $\beta$ and IL-1receptor antagonist (IL-1 RA) genes have both been associated with asthma risk (11). In humans, IL-1 $\beta$ is increased in bronchoalveolar lavage (BAL) fluid and sputum of asthmatics compared to normal volunteers (12), with airway macrophages from asthmatics also having increased expression of IL-1 $\beta$ (13). IL-1 $\beta$ is also increased in BAL fluid from persons with symptomatic asthma vs. those with asymptomatic asthma (14), and there is increased expression of this cytokine in the airways epithelium of asthmatics (15). IL-1 $\beta$ also appears to be involved in the recruitment of airway neutrophils by LPS in rat models $(16,17)$, and is upregulated in the airway after LPS inhalation challenge in humans $(7,18)$. 
IL-1RA is a natural anti-inflammatory cytokine that competes with IL-1 $\beta$ for binding to the IL-1 receptor, preventing IL-1 $\beta$ from binding to the IL- 1 type I receptor. Anakinra is a recombinant form of the human IL-1 receptor antagonist (IL-1 Ra) with a half-life of 4-6 hours. Intratracheal administration of IL-1Ra in rats was shown to inhibit LPS-induced airway neutrophilia (17). Using LPS inhalation challenge as a model of acute neutrophilic asthma, we designed a proof-of-concept study to test the hypothesis that IL-1 $\beta$ blockade with anakinra would suppress airway inflammatory responses to LPS inhalation challenge in healthy volunteers.

\section{Methods}

\section{Volunteer Recruitment and Inclusion Criteria}

This protocol was reviewed and approved by the University of North Carolina Committee on the Rights of Human Subjects (Institutional Review Board) and by the Data and Safety Monitoring Board of the NIAID (AADCRC-UNC-03). This study was also reported to and reviewed by the US Food and Drug Administration (IND 14,669) and listed on clinicaltrials.gov, NCT01369017. This was a double blinded, placebo controlled crossover study comparing the effect of pre-treatment with anakinra on LPS-induced airway neutrophilia (Figure 1) in healthy volunteers with negative methacholine challenge. All subjects underwent a physical examination, routine blood panel with complete blood counts and differential cell count, allergy skin testing, and methacholine challenge (19), as described by Hernandez et al. 2012 (7). All subjects were screened for their ability to provide an adequate induced-sputum sample during their screening session, defined by $>250,000$ cells, $>50 \%$ viability, $<40 \%$ squamous cells. Subjects were excluded if they had contraindications for either inhaled LPS challenge or anakinra administration, including: positive tuberculosis skin test (defined by $>5 \mathrm{~mm}$ induration), tuberculosis (BCG) vaccine or a history of a positive interferon $\gamma$ release assay; immunodeficiency; viral upper respiratory tract infection within 4 weeks of challenge; any acute infection requiring antibiotics within 6 weeks of challenge or fever of unknown origin within 6 weeks of challenge; baseline white blood cell count less than $4.0 \times 10^{9} / \mathrm{L}$ and/or absolute neutrophil count (ANC) less than 1.8 $\times 10^{9} / \mathrm{L}$. Asthmatics were excluded from this proof-of-concept study.

\section{Randomization}

The randomization list was prepared by a biostatistician (Dr. Zhou) using SAS $\odot$ and provided to the UNC Investigational Drug Services (IDS). Only the pharmacist and the biostatistician had access to the randomization schedule.

Subjects were randomized to either anakinra or placebo (saline) injections during the initial study period for 2 days, and received the alternative treatment during the crossover period (Figure 1). There was a minimum washout period of 14 days between the placebo and active treatment periods. Both study staff and subjects were blinded to the treatment regimens.

\section{Anakinra Treatment}

Anakinra was purchased from Biovitrum and stored in the UNC IDS. It was supplied in single-use preservative free, prefilled glass syringes with 27 gauge needles. Each prefilled 
glass syringe contains $0.67 \mathrm{~mL}(100 \mathrm{mg}$ ) of anakinra and is for single use only. The UNC IDS withdrew the prescribed volume into a plastic syringe to provide the $1 \mathrm{mg} / \mathrm{kg}$ for each subject (max $100 \mathrm{mg}$ dose), rounded to 2 decimal points. The placebo injection consisted of saline in a syringe with a 27 -gauge needle. The volume was identical to that of the anakinra dose. The doses were injected by a RN or MD into the right or left arm into the subcutaneous (SQ) tissue.

\section{Endotoxin Inhalation Challenge}

Clinical Center Reference Endotoxin (CCRE), referred to as LPS, was provided by the National Institutes of Health Clinical Center. A dose of 20,000 endotoxin units (EU) was previously shown to induce sputum neutrophils, and was demonstrated to be safe and well tolerated in previous studies (7). Subjects inhaled LPS via a DeVilbiss Ultraneb 99 ultrasonic nebulizer. Induced sputum was obtained 4 hours post-LPS inhalation and processed as previously described (20-23). Cell viability (trypan blue exclusion) and total cell counts were assessed in a Neubauer hemacytometer and differential cell counts were performed on cytocentrifuged cells stained with a modified Wright's stain, (Hema-Stain -3, Fisher Scientific).

\section{Mediator Measurement}

Cytokines from sputum supernatants and from plasma were measured using multi-plex technology (Meso ScaleDiscovery/MSD, Gaithersburg, MD). Each sample was analyzed with the Human Pro-inflammatory 9-Plex Ultra-Sensitive Kit (GM-CSF, IFN- $\gamma$, IL-1 $\beta$, IL-2, IL-6, IL-8, IL-10, IL-12p70, and TNF-a). All sputum supernatant samples were diluted 1:4 and had a final DTT concentration of $<1 \mathrm{mM}$ where no deleterious effects have been observed using the MSD platform. Anakinra levels in plasma and sputum were analyzed using R\&D Systems Quantikine ELISA Human IL-1ra (catalog \# SRA00B, R\&D Systems, Minneapolis, MN). The lowest level of detection was $18.3 \mathrm{pg} / \mathrm{ml}$.

\section{Sample Size Calculations}

Our sample size estimate is based on change in airway \%neutrophils after LPS inhalation compared to baseline. A previous study examined the effect of $440 \mathrm{mcg}$ fluticasone propionate twice a day on LPS-induced sputum neutrophil recruitment(24). The mean difference post-LPS in \%neutrophils between the active and placebo phases was $22 \%$, with a SD $25.8 \%$. Assuming that anakinra treatment would be equivalent to fluticasone propionate in inhibition of LPS-induced airway neutrophilia, we estimated that a sample size of 17 volunteers would be adequate to assess the effect of anakinra on LPS-induced airway neutrophil influx, setting $\beta$ at 0.9 and $\alpha$ at 0.05 . To account for up to $50 \%$ of recruited volunteers not being able to provide an adequate induced sputum sample at screening and for potential for volunteer attrition prior to completion of the study, we set an initial enrollment goal of 40 volunteers. 


\section{Statistical Analysis}

The primary scientific endpoint for this study was the post-LPS challenge \%neutrophils in airway sputum, comparing anakinra to placebo treatment. We hypothesized that anakinra will suppress the LPS-induced increase in neutrophils in HVs.

To analyze the treatment effect on sputum cellularity and sputum cytokine levels (comparing active to placebo treatment), we used a linear mixed model approach described by Jones and Kenward section 3 (25) that considers the above individual tests in a global, unified way where all data are used at the same time. SAS PROC MIXED is used.

Comparisons between post-LPS placebo or active treatment to baseline values were carried out using Wilcoxon-Signed rank tests. Mean and standard error of the mean are represented in the text. Spearman correlation analyses were performed to determine if there was any relationship between \%neutrophils in the sputum and blood, and correlations between changes in \%neutrophils in sputum or blood to IL-1 $\beta$, IL-6, and IL-8 in sputum or blood. Criterion for significance was taken to be $p \leq 0.05$.

\section{Results}

\section{Subject Demographics and Adverse Events}

Twenty-three healthy volunteers were enrolled. Six subjects were excluded after failing the induced sputum screening. Seventeen subjects successfully completed period 1; 15 subjects completed the entire study (Table 1). Eight subjects received active treatment during period 1 ; nine subjects received placebo treatment during period 1 .

Two subjects were withdrawn after period 1 due to study-related adverse events. Subject 10 experienced injection site reactions one week after period 1 (anakinra treatment) was completed. Subject 10 also had a significant reduction in the ANC (from $3.3 \times 10^{9} / \mathrm{L}$ to 1.2 $\times 10^{9} / \mathrm{L}$ ) seven hours after the inhaled LPS challenge during period 1 . The ANC increased to $1.7 \times 10^{9} / \mathrm{L}$ the following day and returned to its baseline level within one week. Subject 12 developed a persistent headache after period 1 and met stopping criteria (received placebo during period 1). No subject experienced significant changes in vital signs or decrements in spirometry related to the inhaled LPS challenge or study treatment (data not shown). The lack of spirometry decrements after inhaled LPS challenge is consistent with our center's previous work using 20,000 EU CCRE as the source of LPS $(18,26)$, unlike other groups using higher doses of LPS, or different sources of LPS $(27,28)$.

Subject 7 reported injection site reactions one week after period 2 was completed. She received anakinra treatment during period 2. All adverse events were reviewed by the PI, the UNC IRB, and the NIAID Data and Safety Monitoring Board. No serious adverse events were reported during this study.

\section{Anakinra treatment did not increase IL-1ra levels in sputum}

Anakinra treatment at a dose of $1 \mathrm{mg} / \mathrm{kg}$ SQ (max $100 \mathrm{mg}$ SQ) did not significantly modulate the levels of IL-1ra in induced sputum (Figure 2A). However, anakinra treatment 
did significantly increase IL-1ra levels in the blood during the active treatment period (Figure 2B) compared to placebo.

\section{Anakinra treatment reduced airway neutrophilia after inhaled LPS challenge}

To determine if systemic administration of anakinra could reduce LPS-induced airway neutrophilia, we first used Wilcoxon-Signed rank tests to compare post-LPS \%neutrophils in placebo or active treatment to baseline values. Inhaled LPS challenge significantly increased sputum \%neutrophils during the placebo period to a mean of $44.5 \% \pm 3.6(\mathrm{p}=0.004)$ compared to baseline values (mean \%neutrophils 29.4 \pm 4.7 ) (Figure 3A). Using the linear mixed model approach, \%neutrophils in LPS-induced sputum after anakinra pretreatment $(32.4 \% \pm 5.1)$ was significantly lower $(80 \%$ change) than after placebo pretreatment. $(\mathrm{p}=0.03)$.

Inhaled LPS challenge significantly increased neutrophils/mg of sputum during the placebo period (mean $1333 \pm 324, \mathrm{p}=0.02$ ) compared to baseline values (mean neutrophils/mg $604 \pm$ 174) (Figure 3B). The neutrophils/mg in LPS-induced sputum after anakinra pretreatment (mean $742 \pm 205)$ were significantly lower than after placebo pretreatment $(\mathrm{p}=0.02)$. There was no significant difference between the active treatment period and baseline values for \%neutrophils $(\mathrm{p}=0.62)$ or neutrophils $/ \mathrm{mg}$ sputum $(\mathrm{p}=0.86)$. The \%macrophages and macrophages/mg of sputum were neither modulated with inhaled LPS treatment nor with anakinra pretreatment (Figures 3C-D).

\section{Anakinra pretreatment reduced the increase in sputum IL-1 $\beta$, IL-6 and IL-8 after inhaled LPS challenge}

Inhaled LPS challenge significantly increased sputum IL-1 $\beta$ (Figure 4A), TNF- $\alpha$ (Figure 4B), and IL-6 (Figure 4C) during the placebo period compared to baseline values. The levels of pro-inflammatory cytokines IL- $1 \beta$, IL-6, and IL-8 in LPS-induced sputum after anakinra pretreatment were significantly lower than after placebo pretreatment by $39 \%, 83 \%$, and $150 \%$, respectively. TNF-a levels in LPS-induced sputum were significantly higher (by 40\%) after anakinra pretreatment than after placebo pretreatment (Figure 4B). Three subjects had increased post-LPS sputum TNF-a levels after anakinra pretreatment. The largest measurement in active treatment in Figure 4B is from subject 10, who was withdrawn after period 1 and thus no data are available for TNF-a response during the placebo treatment period. There were no significant anakinra treatment effects for IL-10, GM-CSF, IFN- $\gamma$, or IL-12p70.

\section{Anakinra pretreatment reduced white blood cell count and absolute neutrophil count}

Inhaled LPS challenge did not significantly increase white blood cell count (WBC) or absolute neutrophil count (ANC) when comparing placebo treatment to baseline values (Table II). Compared to placebo pretreatment, the post-LPS WBC and ANC after anakinra pretreatment were significantly lower by $12 \%$ and $18 \%$, respectively $(\mathrm{p}=0.04)$; ANC was significantly reduced by $18 \%$ during post-LPS anakinra treatment compared to baseline values. Reduced ANC is a known side effect of anakinra treatment. 


\section{Anakinra pretreatment reduced the increase in peripheral blood IL- 6 levels after Inhaled LPS challenge}

Inhaled LPS challenge significantly increased serum IL-6 levels $(\mathrm{p}=0.0006)$ during the placebo treatment period compared to baseline values (Table II). Serum IL-8 levels were significantly increased compared to baseline values during both the placebo and anakinra treatment periods ( $\mathrm{p}<0.01$ for both). Inhaled LPS challenge did not impact serum levels of IL-1 $\beta$ and TNF- $\alpha$ compared to baseline values. Moreover, inhaled LPS challenge did not impact serum levels of IL-10, IL-2, GM-CSF, IFN- $\gamma$, or IL-12p70. Serum IL-6 levels after LPS challenge were significantly lower after anakinra pretreatment than after placebo pretreatment $(\mathrm{p}=.0005)$. There was no anakinra treatment effect on serum IL-8, TNF-a, or IL-1 $\beta$.

\section{No correlation between changes in peripheral blood and sputum neutrophils}

We hypothesized that the reduction in peripheral blood neutrophils during the active treatment phase contributed to the reduction in sputum neutrophils. We performed a Spearman correlation analysis to examine the relationship between the change in peripheral blood \%neutrophils to the change in sputum \%neutrophils during the placebo and active treatment periods (change is defined as the difference between \%neutrophils during placebo/ active minus baseline). There was no correlation between the change in \%peripheral blood neutrophils and the change in \%sputum neutrophils during the active treatment period $(\mathrm{r}=-0.4, \mathrm{p}=0.2, \mathrm{~N}=15)$ or placebo treatment period $(\mathrm{r}=-0.3, \mathrm{p}=0.3, \mathrm{~N}=15)$. Furthermore there was no correlation between the change in sputum \%neutrophils to the change in sputum IL-1 $\beta$, IL-6, or IL-8 during either the active or placebo treatment periods.

\section{Discussion}

The purpose of this early phase human study was to determine if in vivo treatment with anakinra could be a safe and effective intervention in an acute model of neutrophilic airway inflammation induced by LPS inhalation. In healthy volunteers, we found that anakinra treatment decreased LPS-induced \%neutrophils in sputum by $80 \%$. Furthermore, this treatment was well tolerated by our healthy volunteer population.

Although anakinra treatment impacted IL-1ra levels in the blood, it did not appear to affect IL-1ra levels in the airway itself. We suspect that decreased sputum neutrophil counts were due to anakinra effects on neutrophil recruitment to the lung tissue and not on peripheral blood drops in neutrophil counts, as the change in sputum neutrophils did not correlate with the change in peripheral blood neutrophils. As exploratory measures, we assessed proinflammatory cytokine levels in induced sputum that could impact neutrophil recruitment. We found that IL-1 $\beta$, IL-8, and IL- 6 were reduced during the anakinra treatment period compared to the placebo treatment period. We hypothesize that reduced production of these pro-inflammatory mediators affected airway neutrophil recruitment. Since IL-1 $\beta$ has been shown to enhance neutrophil adhesion molecules such as ICAM-1 (29), we speculate that systemic anakinra treatment also impacted neutrophil recruitment through down-regulation of adhesion molecules on vascular endothelium. Although airway TNF-a was elevated during the active treatment period, exclusion of the subject with the highest data point (who 
had received anakinra treatment but not placebo treatment) suggests that there was no significant difference between the active and placebo phases. Unfortunately, we do not know what this subject's airway TNF-a response would have been during the placebo phase.

The efficacy of systemic anakinra administration in this model of acute neutrophilic airway inflammation supports the further study of IL-1 blockade in asthma. Acute neutrophilic airway inflammation is characteristic of viral-induced asthma exacerbations $(30,31)$ but current therapies such as corticosteroids are ineffective in preventing or treating viralinduced asthma exacerbations, likely due to a state of viral-induced steroid resistance (32, 33). Furthermore, many non-Th2 asthmatics have chronic neutrophilic airway inflammation (34), and have been challenging to treat with traditional corticosteroid therapies that target Th2 pathways (35). The current study is limited in studying IL-1 blockade in the context of an acute stimulus of airway neutrophilia. Future clinical studies building on this work would first target alternative pathways to corticosteroids in the management of viral-induced asthma exacerbations. Further work could delineate the potential benefit of this therapy in chronic conditions such as non-Th2 asthma.

However, the implications of IL-1 blockade do not pertain to just neutrophilic inflammation. IL-1 receptor activity is important for eosinophil airway recruitment after allergen challenge (36) through inducing endothelial cell adhesiveness. IL-1 $\beta$ released by eosinophils can augment IL-17 production by CD4+ T cells, with possible consequences in vivo for IL-17mediated airway inflammation (37). Furthermore, IL-1 $\beta$ alone has been shown to induce increased mRNA expression of the eosinophil chemokine, eotaxin, in pulmonary epithelial cells (38), as well as the epithelial cell expression of the mucin genes Muc5B and Muc5AC $(39,40)$. Taken together, these data suggest that IL-1 blockade may be beneficial in both Th2 and non-TH2 asthma through actions on neutrophils, eosinophils, and airway epithelial cell expression of mucins.

This proof-of-concept study assessed the safety of short-term anakinra administration in conjunction with inhaled LPS challenge, as the risks associated with immunomodulatory therapies always need to be weighed against potential benefits. Anakinra is a FDA-approved medication for rheumatoid arthritis (RA) that is also used in the treatment of individuals with gain of function NLRP3 mutations with excessive IL-1 $\beta$ production. In our cohort of 17 individuals who completed period 1 of the study, two subjects (siblings) experienced injection site reactions approximately one week after administration. Injection site reactions are the most common side effect noted with this medication and are transient in nature. However, the most troublesome side effects include peripheral blood neutropenia and increased infection risk. We reduced the risk of clinically significant neutropenia by excluding subjects with an ANC less than $2.0 \times 10^{9} / \mathrm{L}$ at baseline, as the package insert (41) noted that the majority of RA patients with an ANC $<1.0 \times 10^{9} / \mathrm{L}(0.31 \%$ of RA patients $)$ after treatment had baseline ANC less than 2.0. The lowest ANC we noted in our study population was $1.2 \times 10^{9} / \mathrm{L}$, and had increased to $1.7 \times 10^{9} / \mathrm{L}$ the following day (after the last dose of anakinra).

Our study cohort did not experience infections that were attributable to anakinra in this short-term study. We hypothesize that anakinra could be employed in two fashions. One 
would be chronic therapy in the context of severe, chronic steroid-resistant neutrophilic asthma. In this setting, the potential for anakinra-induced immunosuppression and increased risk for infection would need to be carefully studied as it is known that when used on a daily basis to treat RA, subjects with IL-1ra blockade do experience a significantly increased risk of infections (41). However, a second use for anakinra in asthma would focus on mitigating severe, acute exacerbations of asthma. Indeed, our protocol was developed to mimic inflammatory events likely in acute exacerbation of airway disease. With this more limited approach, the risk on acute or long term immunosuppression would be minimized. Regardless, in any future applications for anakinra in asthma, patient selection for potential IL-1 blockade would need to include a thoughtful risk assessment for these factors in conjunction with the dosing frequency of this drug.

In conclusion, we found that IL-1 blockade with anakinra extensively reduced neutrophil recruitment to the airway after inhaled LPS challenge in a phase I study with healthy volunteers. Although systemic anakinra administration did not modulate IL-1ra levels in the airway, anakinra did reduce levels of pro-inflammatory mediators produced in the airway. The overall favorable safety profile of short-term anakinra treatment (due in part to its short half-life) coupled with its efficacy against acute airway neutrophilia warrant the study of IL-1 blockade as part of the therapeutic strategy in airway diseases characterized by acute airway neutrophilic inflammation, such as asthma exacerbations associated with viral infection or environmental exposure to LPS-containing particles and bioaerosols.

\section{Acknowledgments}

Funding Sources: MLH is supported by NIEHS K23-ES021745; KM, MA, HZ, HZ, and DBP are supported by NIAID U19AI077437.

\section{References}

1. Gern JE, Busse WW. Relationship of viral infections to wheezing illnesses and asthma. Nat Rev Immunol. 2002 Feb; 2(2):132-8. [PubMed: 11910895]

2. Peden DB. The epidemiology and genetics of asthma risk associated with air pollution. J Allergy Clin Immunol. 2005 Feb; 115(2):213-9. quiz 20. [PubMed: 15696070]

3. Reed CE, Milton DK. Endotoxin-stimulated innate immunity: A contributing factor for asthma. J Allergy Clin Immunol. 2001 Aug; 108(2):157-66. [PubMed: 11496229]

4. Alexis NE, Brickey WJ, Lay JC, Wang Y, Roubey RA, Ting JP, et al. Development of an inhaled endotoxin challenge protocol for characterizing evoked cell surface phenotype and genomic responses of airway cells in allergic individuals. Ann Allergy Asthma Immunol. 2008 Mar; 100(3): 206-15. [PubMed: 18426139]

5. Alexis NE, Lay JC, Almond M, Bromberg PA, Patel DD, Peden DB. Acute LPS inhalation in healthy volunteers induces dendritic cell maturation in vivo. J Allergy Clin Immunol. 2005 Feb; 115(2):345-50. [PubMed: 15696093]

6. Hernandez ML, Harris B, Lay JC, Bromberg PA, Diaz-Sanchez D, Devlin RB, et al. Comparative airway inflammatory response of normal volunteers to ozone and lipopolysaccharide challenge. Inhal Toxicol. 2010 Jul; 22(8):648-56. [PubMed: 20540623]

7. Hernandez ML, Herbst M, Lay JC, Alexis NE, Brickey WJ, Ting JP, et al. Atopic asthmatic patients have reduced airway inflammatory cell recruitment after inhaled endotoxin challenge compared with healthy volunteers. The Journal of allergy and clinical immunology. 2012 Oct; 130(4):869-76. e2. [PubMed: 22770265] 
8. Wood LG, Simpson JL, Wark PA, Powell H, Gibson PG. Characterization of innate immune signalling receptors in virus-induced acute asthma. Clinical and experimental allergy. 2011 May; 41(5):640-8. [PubMed: 21129050]

9. Baines KJ, Simpson JL, Wood LG, Scott RJ, Gibson PG. Transcriptional phenotypes of asthma defined by gene expression profiling of induced sputum samples. The Journal of allergy and clinical immunology. 2011 Jan; 127(1):153-60. 60 e1-9. [PubMed: 21211650]

10. Wenzel SE, Barnes PJ, Bleecker ER, Bousquet J, Busse W, Dahlen SE, et al. A randomized, double-blind, placebo-controlled study of tumor necrosis factor-alpha blockade in severe persistent asthma. American journal of respiratory and critical care medicine. 2009 Apr 1; 179(7):549-58. [PubMed: 19136369]

11. Gohlke H, Illig T, Bahnweg M, Klopp N, Andre E, Altmuller J, et al. Association of the interleukin-1 receptor antagonist gene with asthma. American journal of respiratory and critical care medicine. 2004 Jun 1; 169(11):1217-23. [PubMed: 15020290]

12. Konno S, Gonokami Y, Kurokawa M, Kawazu K, Asano K, Okamoto K, et al. Cytokine concentrations in sputum of asthmatic patients. International archives of allergy and immunology. 1996 Jan; 109(1):73-8. [PubMed: 8527954]

13. Pujol JL, Cosso B, Daures JP, Clot J, Michel FB, Godard P. Interleukin-1 release by alveolar macrophages in asthmatic patients and healthy subjects. Int Arch Allergy Appl Immunol. 1990; 91(2):207-10. [PubMed: 2341202]

14. Broide DH, Lotz M, Cuomo AJ, Coburn DA, Federman EC, Wasserman SI. Cytokines in symptomatic asthma airways. The Journal of allergy and clinical immunology. 1992 May; 89(5): 958-67. [PubMed: 1374772]

15. Sousa AR, Lane SJ, Nakhosteen JA, Lee TH, Poston RN. Expression of interleukin-1 beta (IL-1beta) and interleukin-1 receptor antagonist (IL-1ra) on asthmatic bronchial epithelium. American journal of respiratory and critical care medicine. 1996 Oct; 154(4 Pt 1):1061-6. [PubMed: 8887608]

16. Ulich TR, Guo KZ, Irwin B, Remick DG, Davatelis GN. Endotoxin-induced cytokine gene expression in vivo. II. Regulation of tumor necrosis factor and interleukin-1 alpha/beta expression and suppression. The American journal of pathology. 1990 Nov; 137(5):1173-85. [PubMed: 2240164]

17. Ulich TR, Yin SM, Guo KZ, del Castillo J, Eisenberg SP, Thompson RC. The intratracheal administration of endotoxin and cytokines. III. The interleukin-1 (IL-1) receptor antagonist inhibits endotoxin- and IL-1-induced acute inflammation. The American journal of pathology. 1991 Mar; 138(3):521-4. [PubMed: 1825745]

18. Hernandez ML, Wagner JG, Kala A, Mills K, Wells HB, Alexis NE, et al. Vitamin E, gammatocopherol, reduces airway neutrophil recruitment after inhaled endotoxin challenge in rats and in healthy volunteers. Free radical biology \& medicine. 2013 Jul.60:56-62. [PubMed: 23402870]

19. Crapo RO, Casaburi R, Coates AL, Enright PL, Hankinson JL, Irvin CG, et al. Guidelines for methacholine and exercise challenge testing-1999. This official statement of the American Thoracic Society was adopted by the ATS Board of Directors, July 1999. American journal of respiratory and critical care medicine. 2000 Jan; 161(1):309-29. [PubMed: 10619836]

20. Alexis NE, Zhou H, Lay JC, Harris B, Hernandez ML, Lu TS, et al. The glutathione-S-transferase $\mathrm{Mu} 1$ null genotype modulates ozone-induced airway inflammation in human subjects. J Allergy Clin Immunol. 2009 Dec; 124(6):1222-8. e5. [PubMed: 19796798]

21. Lay JC, Alexis NE, Kleeberger SR, Roubey RA, Harris BD, Bromberg PA, et al. Ozone enhances markers of innate immunity and antigen presentation on airway monocytes in healthy individuals. J Allergy Clin Immunol. 2007 Sep; 120(3):719-22. [PubMed: 17586033]

22. Alexis NE, Eldridge MW, Peden DB. Effect of inhaled endotoxin on airway and circulating inflammatory cell phagocytosis and CD11b expression in atopic asthmatic subjects. J Allergy Clin Immunol. 2003 Aug; 112(2):353-61. [PubMed: 12897742]

23. Alexis NE, Lay JC, Zeman K, Bennett WE, Peden DB, Soukup JM, et al. Biological material on inhaled coarse fraction particulate matter activates airway phagocytes in vivo in healthy volunteers. J Allergy Clin Immunol. 2006 Jun; 117(6):1396-403. [PubMed: 16751003] 
24. Alexis NE, Peden DB. Blunting airway eosinophilic inflammation results in a decreased airway neutrophil response to inhaled LPS in patients with atopic asthma: a role for CD14. J Allergy Clin Immunol. 2001 Oct; 108(4):577-80. [PubMed: 11590384]

25. Jones, BK.; Kenward, MG. Design and Analysis of Crossover Trials. Second. Chapman and Hall/ CRC; 2003.

26. Hernandez ML, Lay JC, Harris B, Esther CR Jr, Brickey WJ, Bromberg PA, et al. Atopic asthmatic subjects but not atopic subjects without asthma have enhanced inflammatory response to ozone. $\mathrm{J}$ Allergy Clin Immunol. 2010 Sep; 126(3):537-44. e1. [PubMed: 20816188]

27. Kline JN, Cowden JD, Hunninghake GW, Schutte BC, Watt JL, Wohlford-Lenane CL, et al. Variable airway responsiveness to inhaled lipopolysaccharide. American journal of respiratory and critical care medicine. 1999 Jul; 160(1):297-303. [PubMed: 10390415]

28. Leaker BR, Barnes PJ, O'Connor B. Inhibition of LPS-induced airway neutrophilic inflammation in healthy volunteers with an oral CXCR2 antagonist. Respiratory research. 2013; 14:137. [PubMed: 24341382]

29. Yang CM, Luo SF, Hsieh HL, Chi PL, Lin CC, Wu CC, et al. Interleukin-1beta induces ICAM-1 expression enhancing leukocyte adhesion in human rheumatoid arthritis synovial fibroblasts: involvement of ERK, JNK, AP-1, and NF-kappaB. Journal of cellular physiology. 2010 Aug; 224(2):516-26. [PubMed: 20432452]

30. Dougherty RH, Fahy JV. Acute exacerbations of asthma: epidemiology, biology and the exacerbation-prone phenotype. Clinical and experimental allergy. 2009 Feb; 39(2):193-202. [PubMed: 19187331]

31. Stoppelenburg AJ, Salimi V, Hennus M, Plantinga M, Huis in 't Veld R, Walk J, et al. Local IL-17A potentiates early neutrophil recruitment to the respiratory tract during severe RSV infection. PLoS One. 2013; 8(10):e78461. [PubMed: 24194936]

32. Kimura G, Ueda K, Eto S, Watanabe Y, Masuko T, Kusama T, et al. Toll-like receptor 3 stimulation causes corticosteroid-refractory airway neutrophilia and hyperresponsiveness in mice. Chest. 2013 Jul; 144(1):99-105. [PubMed: 23348232]

33. Papi A, Contoli M, Adcock IM, Bellettato C, Padovani A, Casolari P, et al. Rhinovirus infection causes steroid resistance in airway epithelium through nuclear factor kappaB and c-Jun N-terminal kinase activation. The Journal of allergy and clinical immunology. 2013 Nov; 132(5):1075-85. e6. [PubMed: 23871663]

34. Baines KJ, Simpson JL, Wood LG, Scott RJ, Fibbens NL, Powell H, et al. Sputum gene expression signature of 6 biomarkers discriminates asthma inflammatory phenotypes. The Journal of allergy and clinical immunology. 2014 Feb 27.

35. Wenzel SE. Asthma phenotypes: the evolution from clinical to molecular approaches. Nature medicine. 2012 May; 18(5):716-25.

36. Broide DH, Campbell K, Gifford T, Sriramarao P. Inhibition of eosinophilic inflammation in allergen-challenged, IL-1 receptor type 1-deficient mice is associated with reduced eosinophil rolling and adhesion on vascular endothelium. Blood. 2000 Jan 1; 95(1):263-9. [PubMed: 10607711]

37. Esnault S, Kelly EA, Nettenstrom LM, Cook EB, Seroogy CM, Jarjour NN. Human eosinophils release IL-1ss and increase expression of IL-17A in activated CD4+ T lymphocytes. Clinical and experimental allergy. 2012 Dec; 42(12):1756-64. [PubMed: 23181791]

38. Lilly CM, Nakamura H, Kesselman H, Nagler-Anderson C, Asano K, Garcia-Zepeda EA, et al. Expression of eotaxin by human lung epithelial cells: induction by cytokines and inhibition by glucocorticoids. The Journal of clinical investigation. 1997 Apr 1; 99(7):1767-73. [PubMed: 9120022]

39. Fujisawa T, Chang MM, Velichko S, Thai P, Hung LY, Huang F, et al. NF-kappaB mediates IL-1beta- and IL-17A-induced MUC5B expression in airway epithelial cells. American journal of respiratory cell and molecular biology. 2011 Aug; 45(2):246-52. [PubMed: 20935193]

40. Fujisawa T, Velichko S, Thai P, Hung LY, Huang F, Wu R. Regulation of airway MUC5AC expression by IL-1beta and IL-17A; the NF-kappaB paradigm. Journal of immunology. 2009 Nov 15; 183(10):6236-43. 
41. Biovitrum. US Food and Drug Administration; 2013. Physician Package Insert Kineret (Anakinra). http://www.accessdata.fda.gov/drugsatfda_docs/label/2013/103950s5150lbl.pdf

\section{Abbreviations}

$\begin{array}{ll}\text { LPS } & \text { Lipopolysaccharide } \\ \text { IL-1ra } & \text { Interleukin-1 receptor antagonist } \\ \text { CCRE } & \text { Clinical Center Reference Endotoxin } \\ \text { EU } & \text { Endotoxin Units } \\ \text { WBC } & \text { White Blood Cell } \\ \text { ANC } & \text { Absolute Neutrophil Count } \\ \text { BAL } & \text { Bronchoalveolar Lavage } \\ \text { COPD } & \text { Chronic Obstructive Pulmonary Disease } \\ \text { RA } & \text { Rheumatoid Arthritis }\end{array}$




\section{Clinical Implications}

Our results suggest that IL-1 blockade with the interleukin-1 receptor antagonist, anakinra, is safe and effective in reducing airway neutrophilia after an innate immune stimulus. 


\section{Phase I Human Study Design}

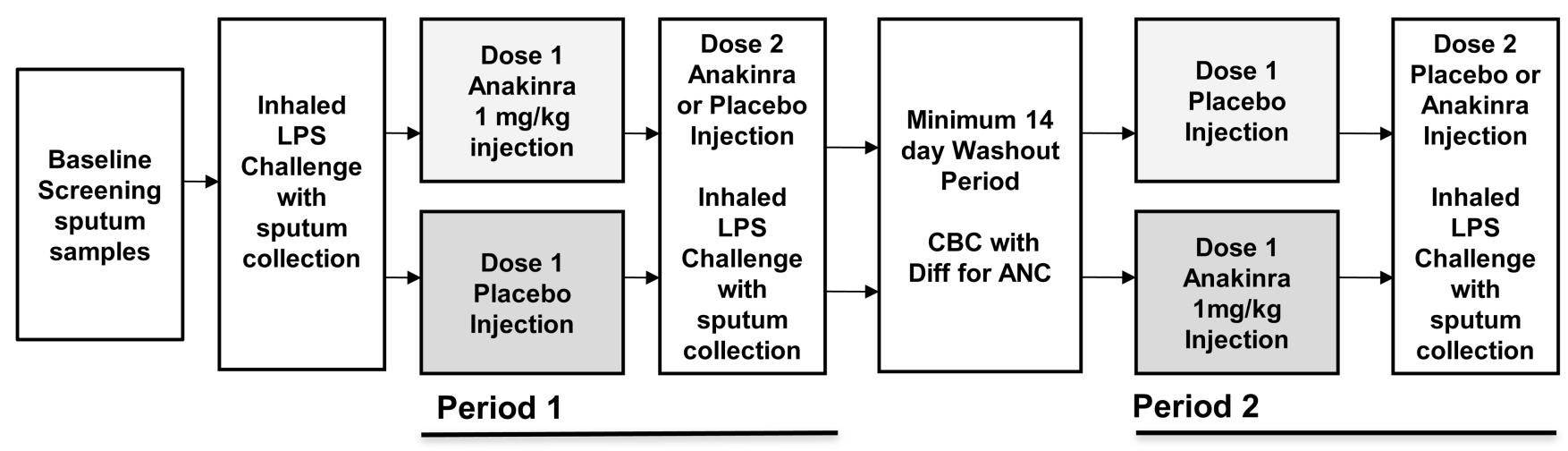

Figure 1. Phase I study design in healthy human volunteers

Randomized, placebo controlled crossover study of the interleukin-1 receptor antagonist, anakinra, and saline (placebo) in 17 healthy volunteers. Subjects were challenged with inhaled LPS (20,000 EU of CCRE), followed by sputum induction 4 hours after the LPS challenge. 

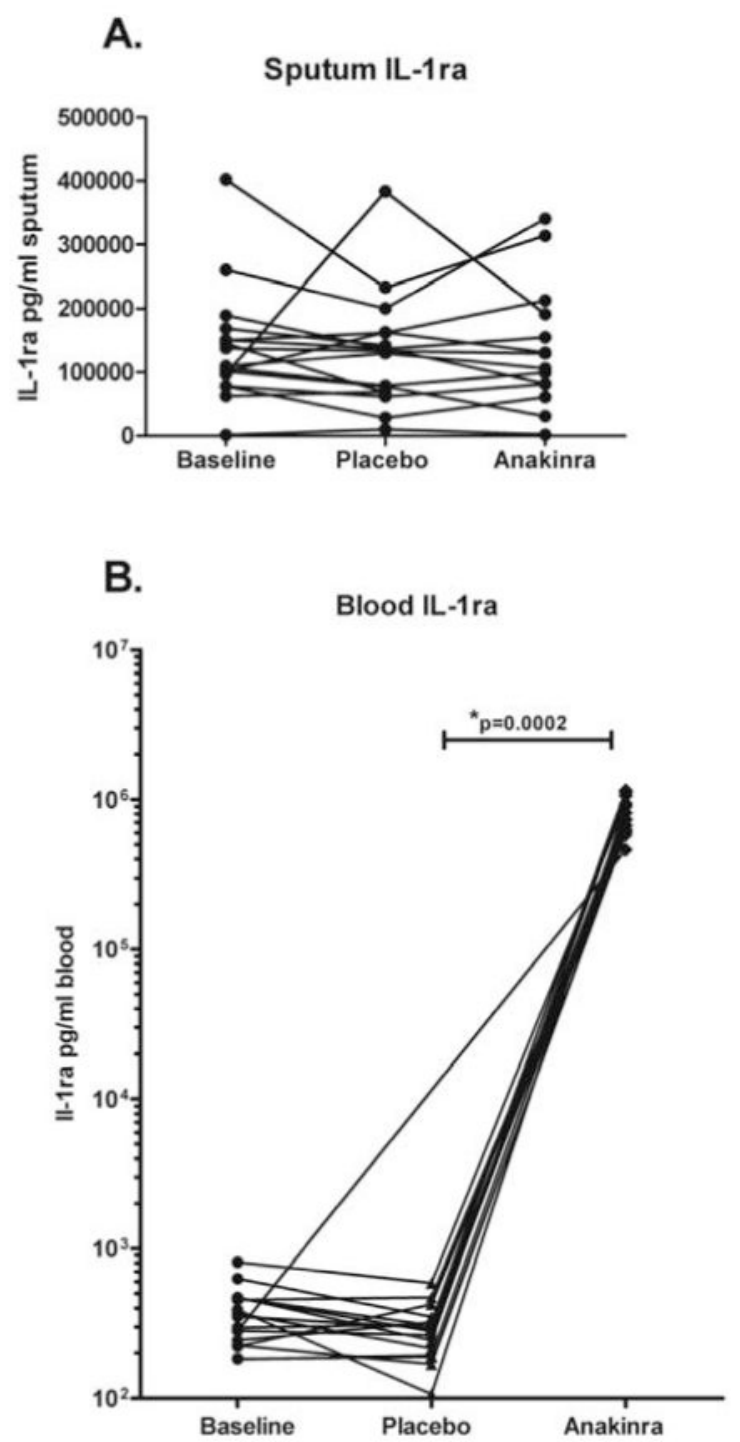

Figure 2. Interleukin-1 receptor antagonist levels are increased in blood, but not sputum with anakinra treatment

Levels of interleukin-1 receptor antagonist were measured in sputum (A) and blood (B) at baseline visit, and 4 hours after inhaled LPS challenge with anakinra or placebo treatment. A linear mixed model approach was used to calculate the treatment effect comparing anakinra to placebo 

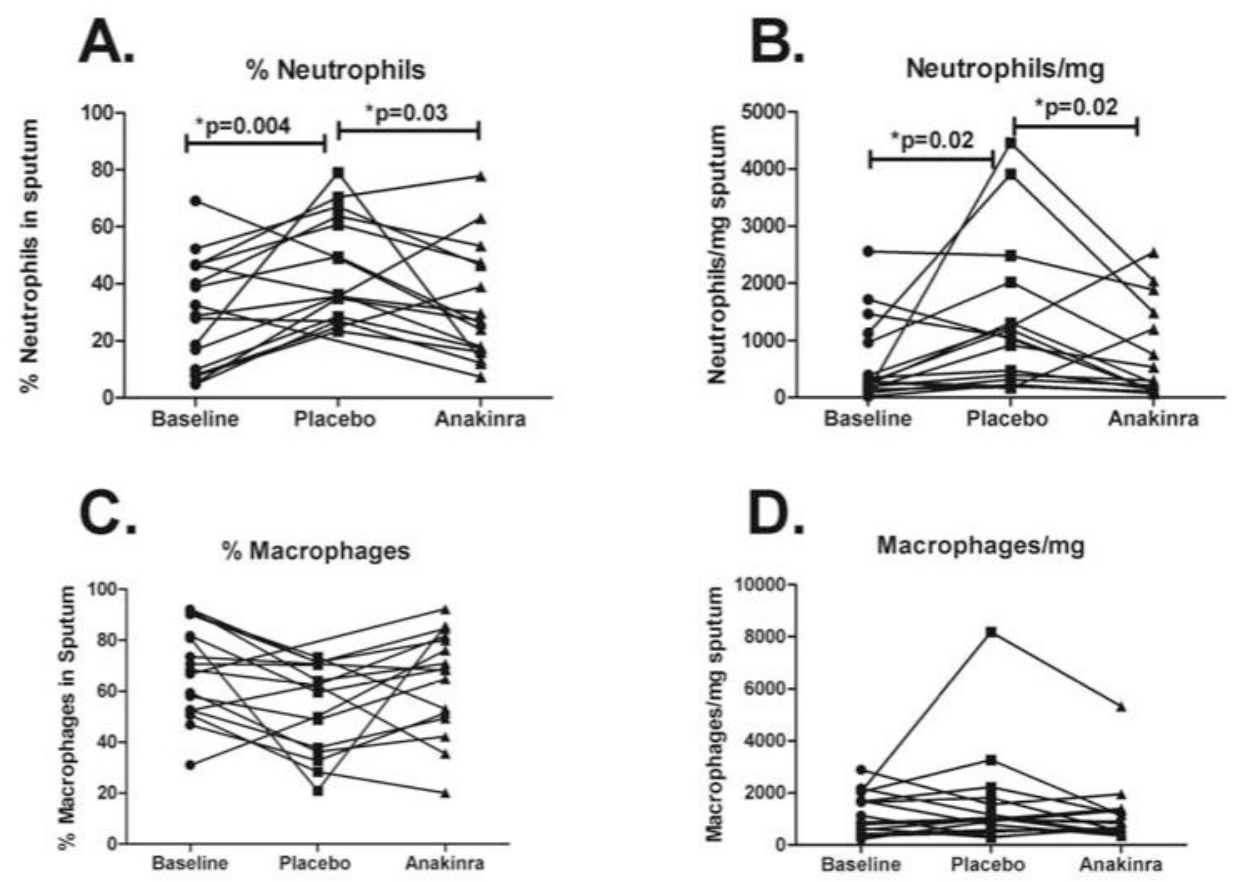

Figure 3. Anakinra pretreatment reduces airway neutrophilia after LPS exposure Percent neutrophils (A), neutrophils per mg sputum (B), percent macrophages (C), and macrophages per mg sputum were determined from induced sputum samples taken at baseline visit, and 4 hours after inhaled LPS challenge with anakinra or placebo treatment. Wilcoxon-signed rank tests were used to compare either post-LPS anakinra or placebo levels to baseline levels. A linear mixed model approach was used to calculate the treatment effect comparing anakinra to placebo 

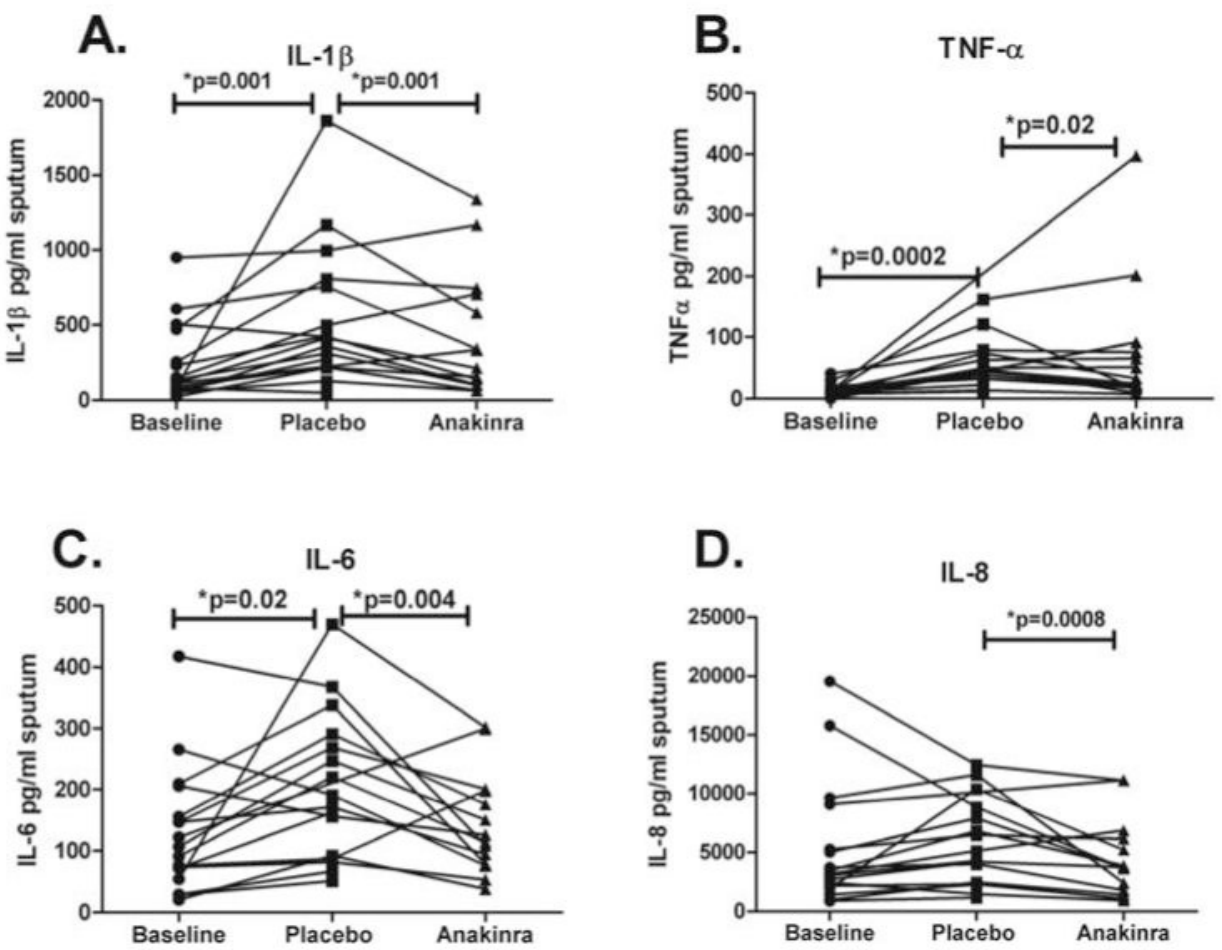

Figure 4. Anakinra pretreatment reduced the increase in sputum IL-1 $\beta$, IL-6, and IL-8 after inhaled LPS challenge

Levels of IL-1 $\beta$ (A), TNF-a (B), IL-6 (C), and IL-8 (D) were measured from induced sputum taken at baseline visit, and 4 hours after inhaled LPS challenge with anakinra or placebo treatment. Wilcoxon-signed rank tests were used to compare either post-LPS anakinra or placebo levels to baseline levels. A linear mixed model approach was used to calculate the treatment effect comparing anakinra to placebo. 
Table I

Enrollment and Demographics of Healthy Volunteers

\begin{tabular}{|c|c|}
\hline Clinical Characteristics of Subjects Fulfilling Inclusion Criteria & 17 \\
\hline $\mathrm{N}$ & $28 \pm 6$ \\
\hline Age (y), mean (SD) & $12 \mathrm{~F} / 5 \mathrm{M}$ \\
\hline Gender & $\begin{array}{c}13 \text { Caucasian } \\
\text { African American } \\
1 \text { Latino }\end{array}$ \\
\hline Race & $25.5 \pm 5.0$ \\
\hline BMI & None \\
\hline Atopy & $\downarrow$ \\
\hline \multicolumn{2}{|c|}{ Withdrawals after Period 1 } \\
\hline \multicolumn{2}{|c|}{$\begin{array}{c}\text { Female: Injection site reactions 7 days after finishing period 1. ANC dropped from 3.3 } \times 10 / \mathrm{L} \text { to } 1.2 \times 10 / \mathrm{L} \text { during period } 1 \text { (assigned to } \\
\text { Active Treatment Period 1). } \\
\text { Female: Headache after finishing period 1 (assigned to Placebo Treatment Period 1) }\end{array}$} \\
\hline
\end{tabular}




\section{Table II}

White Blood Cell (WBC), Absolute Neutrophil Count, and serum cytokines.

\begin{tabular}{|c|c|c|c|}
\hline Mean \pm SD & Baseline & Post LPS Placebo & Post LPS Anakinra \\
\hline $\mathrm{WBC} \times 10^{9} / \mathrm{L}$ & $6.5 \pm 1.6$ & $6.8 \pm 1.6$ & $6.0 \pm 1.5^{*}$ \\
\hline Absolute Neutrophil Count $\times 10^{9} / \mathrm{L}$ & $3.9 \pm 1.3$ & $3.9 \pm 1.3$ & $3.2 \pm 1.1^{* \dagger}$ \\
\hline $\mathrm{IL}-1 \beta(\mathrm{pg} / \mathrm{ml})$ & $0.06 \pm 0.04$ & $0.05 \pm 0.05$ & $0.08 \pm 0.04$ \\
\hline $\mathrm{IL}-6(\mathrm{pg} / \mathrm{ml})$ & $0.6 \pm 0.5$ & $1.3 \pm 0.8^{\dagger}$ & $0.6 \pm 0.5^{* *}$ \\
\hline $\mathrm{IL}-8(\mathrm{pg} / \mathrm{ml})$ & $1.7 \pm 0.7$ & $2.7 \pm 1.1^{\dagger}$ & $2.9 \pm 1.1^{\dagger}$ \\
\hline TNF- $\mathrm{a}(\mathrm{pg} / \mathrm{ml})$ & $2.2 \pm 0.9$ & $2.2 \pm 0.9$ & $2.4 \pm 0.8$ \\
\hline
\end{tabular}

* Denotes $\mathrm{p}<0.04$ comparing post-CCRE anakinra to placebo treatment using Wilcoxon Signed Rank Tests.

**

denotes $\mathrm{p}=0.0005$ comparing post-CCRE anakinra to placebo treatment.

${ }^{\dagger}$ denotes $\mathrm{p}<0.01$ and

${ }^{\dagger \dagger}$ denotes $\mathrm{p}=0.04$ comparing post-CCRE anakinra treatment to baseline values. 